\title{
Artigo
}

\section{Memorias afrodescendientes y africanas en Argentina: algunas consideraciones teóricas}

Paola Carolina Monkevicius (CONICET, Universidad

Nacional de La Plata)

\section{INTRODUCCIÓN}

Andreas Huyssen afirma que desde la década de 1980 se ha producido un desplazamiento en la experiencia y en la percepción del tiempo'. La puesta en foco sobre el pasado, tanto dentro como fuera del campo académico, ha derivado en el llamado "boom de la memoria". En particular, la memoria entendida como fenómeno social y cultural se ha convertido en objeto privilegiado de diversas disciplinas, a pesar de las dificultades para establecer definiciones y categorías analíticas precisas y consensuadas. A su vez, ha sido objeto de reflexión, contestación y negociación por parte de diversos colectivos sociales que han apelado a la memoria como garante de legitimidad en el marco de la disputa política.

Con respecto a esto, y considerando el contexto argentino, advertimos un creciente proceso de resignificación del pasado desde diversos grupos subalternizados a partir de la consecución de la democracia a principios de la década de 1980. Los sucesos acontecidos durante la última dictadura cívico-militar (1976-1983) han sido el eje principal sobre el cual gravitó este proceso. En palabras de Jaume (2000:67), “la preocupación social reflejada en la recordación e insistencia en traer al presente el pasado reciente y dramático instaló en las ciencias sociales el problema de la memoria y los modos en que los distintos estratos sociales y políticos la constituyen, recrean y utilizan políticamente" ${ }^{2}$. En la última década asistimos a una profundización de este fenómeno siendo que el Estado nacional, en diálogo con los organismos de derechos humanos, ha impulsado el debate sobre el pasado reciente y ha constituido a la memoria como objeto de políticas públicas. En consecuencia, se observa un interés renovado sobre el trabajo de memoria, a la manera tanto de herramienta de accionar político cívico-estatal, como de objeto de estudio académico, debido a su rol en la "constitución simbólica de los grupos sociales y sus identidades" (Jaume 2000). En este contexto, diversos grupos han recurrido a la memoria como mecanismo sobre el 
reparaciones, en tanto colectivos olvidados/excluidos del relato oficial y, en consecuencia, del goce de los derechos de una ciudadanía plena. Esto ha despertado el interés de la antropología, por ejemplo, sobre cómo los procesos de identificación indígenas, a nivel regional, nacional e internacional, se dirimen mayormente en las resignificaciones del pasado ${ }^{3}$. Si bien los pueblos originarios se han posicionado, en varios aspectos, a la vanguardia en el uso de las memorias sociales como mecanismos de visibilización, identificación étnica y movilización social dentro del Estado-nación, también observamos que estos procesos se han diversificado hacia otros actores.

Con el objetivo de reflexionar sobre estas dinámicas es que nos proponemos revisitar algunos debates y formas de aprehensión sobre las memorias desde una perspectiva antropológica interesada en analizar cómo el pasado es usado por colectivos subalternizados en contextos hegemónicos nacionales donde se profundizan las fisuras en el relato oficial y se abren nuevos espacios para las "otras" memorias. Específicamente, nos interesa indagar sobre la relación entre las resignificaciones y los usos del pasado, y los recientes procesos de identificación y visibilización "afro" en Argentina. Si bien categorías como olvido y silencio respecto de la historia de los negros en Argentina han estado presentes en gran parte de la producción académica en torno de la denominada "cuestión afro", consideramos que en la mayoría de los casos se apela a éstas sin una problematización ni una definición respecto de los significados, alcances y dinámicas implicadas en su uso como herramientas de análisis. En consecuencia, este artículo se propone brindar un aporte desde los estudios de memoria social, en tanto herramienta analítica, para un mayor entendimiento de la "reaparición" de los negros en Argentina. Para ello, realizaremos una exploración teórica posicionada sobre los actuales procesos de reinscripción de las memorias "afro" en el marco de un ejercicio revisionista del pasado nacional y de las "otras" memorias.

Con este fin, en primer lugar, situaremos las memorias de afrodescendientes y africanos en el marco nacional desde donde operan para delimitar y marcar contornos culturales. Luego dedicaremos un apartado a encuadrar teóricamente a las memorias especificando categorías y conceptos. Finalmente reuniremos las discusiones planteadas para proponer una perspectiva antropológica de los procesos de memoria social que aporte al conocimiento del complejo campo de los denominados "estudios afro" en Argentina, en particular sobre los procesos de invisibilización-revisibilización, discriminación y reclamos de derechos e igualdad ciudadana.

Previamente creo necesario aclarar que la revisión teórica y las reflexiones acerca de su pertinencia y relevancia para indagar sobre los denominados "afros" en Argentina surgen a partir de una investigación empírica realizada desde el año 2010. Nuestro referente principal se encuentra compuesto por afrodescendientes e inmigrantes africanos que participan de asociaciones y agrupaciones étnicas, políticas y culturales ${ }^{4}$ y, que debido a ello, incorporan sus discursos al escenario público interpelando, en gran medida, al Estado argentino. Aunque se adscriben fundamentalmente como "afros" integrando una "comunidad", debemos reconocer las dificultades de unificar y homogenizar un colectivo complejamente diverso, compuesto por afrodescendientes producto de la trata esclavista (afroargentinos y afroamericanos), inmigrantes africanos (llegados durante el siglo XX -caboverdianos-, y actuales) y sus descendientes, cuyo principal punto en común, como señala Frigerio (2010) es que son visualizados por la sociedad argentina como "negros". El riesgo de simplificar este fenómeno bajo una sola categoría abarcadora implicaría negar las necesidades, derroteros y expectativas de cada sector integrante dificultando la puesta en marcha 
de políticas específicas. La diversidad de actores y de adscripciones impide asimismo pensar al colectivo como un único productor de la "memoria negra" en Argentina. En lugar de ello, lo consideramos en su complejidad y dinámica dando como resultado una pluralidad de memorias, narrativas y discursos acerca del pasado en articulación, complementación pero también en conflicto. No obstante, la investigación realizada nos permite afirmar que existe, como elemento común, una persistente apelación al pasado a la manera de eje sobre el cual legitimar y autorizar identificaciones y demandas, especialmente desde los sectores de liderazgo. Esto se produce en un contexto de revisión y contestación de narrativas oficiales, como veremos en el siguiente apartado.

Creemos, por tanto, que estos "nuevos" sentidos del pasado deben ser objeto de un abordaje antropológico con el fin de comprender los actuales procesos de visibilización de los negros en Argentina.

\section{HISTORIA HEGEMÓNICA Y OLVIDO}

Como sostienen los Comaroff (2011:183), en los últimos tiempos, los reclamos por la identidad han puesto en duda las clásicas narrativas nacionales revelando su carácter heterogéneo, diverso y conflictivo. Se debilita así un imaginario fuertemente arraigado desde los procesos de constitución de las naciones modernas: la sinonimia entre cultura e identidad (Grimson 2010). Esto promueve la conformación de nuevas identificaciones en un marco que se pensaba consensuado y amparado por una "misma cultura" y una "misma historia". Lo que interesa destacar aquí es que esos relatos nacionales "fueron desacreditados, no solo por procesos de globalización, sino por dinámicas emergentes" como aquella que involucra a los grupos "afro", "que repusieron la distancia entre territorio jurídico, la cultura en el sentido tradicional y las identidades." (Grimson 2010:66).

Nuevas identidades o re-identificaciones requirieron de nuevas (o renovadas) pertenencias culturales y es allí donde surgen las memorias como anclaje (Anderson 1997; Brow 1990). No es casual entonces que se revitalicen debates sobre la historia argentina y el silenciamiento operante sobre las memorias subordinadas a ese relato hegemónico, en particular, sobre la presencia del componente africano en la conformación de la nación y su continuidad hasta el presente.

\subsection{LA MEMORIA (DES)LEGITIMADA}

Es pertinente comenzar este apartado diciendo que las construcciones nacionales del pasado se presentan como las formas más legítimas que adquieren las memorias colectivas (Pollak 1989). Esta legitimidad, no obstante, se encuentra amenazada, en mayor o menor medida, por otras versiones que la disputan desde la arena política (Brow 1990; Popular Memory Group 1982). Por esta razón, los procesos de nacionalización debieron poner en marcha fuertes mecanismos ideológicos tendientes a generar sentido de pertenencia transformando "los múltiples 'pasados' de su historia en una herencia nacional común" (Briones 1995:45) o un "fondo común de referencias" 
(Pollak 1989), un discurso unificado y autorizado para ser transmitido por los “mecanismos estatales de generación de propuestas de identidad" (Juliano 1992). Como sostiene Pollak (1989), para que esto sea posible la memoria hegemónica requiere credibilidad, aceptación y un intenso trabajo de organización superador del "simple montaje ideológico" que debilitaría y revelaría el carácter construido y heterogéneo de las memorias. Esta necesidad convirtió a las "instituciones del Estado" (educativas, administrativas y judiciales) en "agencias de Estado" dentro de un proceso histórico muy específico de sujeción" que tiende a legitimar lo ilegítimo (Corrigan y Sayer 2007) 5 .

¿En qué consiste esta ilegitimidad entonces? En reconfigurar las diversidades, las distintas versiones del pasado con sus propias historicidades y contextos sociales de significación "normalizando"6 las memorias tras una “historia ficticia"7. Pero cada formación nacional apela a diferentes criterios étnicos, sociales o políticos que devienen de procesos históricos "caracterizados por sistemas particulares de poder y autoridad que consideran creíbles solo ciertas formas de herencia" (Olwig 1999:370) mientras invisibilizan o silencian otras. En otros términos, la idea de proceso impide hablar de formas estables y permanentes de construcciones de alteridad (Briones 2005) sino que existen marchas y contramarchas, prácticas hegemónicas históricamente cambiantes (Gillis 1994; Briones 1998) donde operan "reconstrucciones" y "reimaginaciones" de homogeneidad y diversidad cultural (Handler 1994:38)

A partir de mediados del siglo XIX y particularmente desde $1880^{\circ}$, el Estado argentino puso en marcha su "máquina de aplanar" las diferencias (Segato 2007) y esta aplanadora cultural se constituyó en gran medida como una "aplanadora mnemónica" (Monkevicius en prensa) que anulaba "otros" sentidos del pasado para imponer, principalmente a través de la educación pública, una sola y "neutral" memoria hegemónica10 que aseguraría la integración al colectivo nacional, en tanto "crisol de razas" (europeas), y, en consecuencia, una igualdad en la asignación de derechos a los "argentinos" en tanto ciudadanos. Como en otros Estados americanos, aunque de forma exacerbada, las elites argentinas pugnaron por concretizar el ideal de blanqueamiento entendido como "puerta de entrada" a la civilización. Según Segato (2007:49), "el estado nacional, frente a la fractura capital/ interior ${ }^{11} \mathrm{y}$ a los contingentes de inmigrantes europeos ${ }^{12}$ que se agregaron, presionó para que la nación se comportase como una unidad étnica dotada de una cultura singular propia homogénea y reconocible." Por tanto, esta representación "europeísta"13 de la nación lejos se encuentra de la posibilidad de concebir el mestizaje, la pluralidad o las interpenetraciones culturales. El blanco de origen europeo se convirtió entonces en una "trampa de la auto-imagen" en relación con el "otro" que posibilitaba congelar y simplificar la diversidad inherente a todo colectivo nacional (Ribeiro 2002). La unidad étnico-racial se legitimaba por una unidad histórica, un mismo origen, y aquellos sentidos del pasado que no se ajustaran al ideario nacional debían replegarse, silenciarse y transmitirse en forma privada o a través de canales no autorizados. Esto sucedió particularmente con las memorias de la presencia negra en Argentina, constituyéndose "el negro en metáfora de toda diferencia, toda etnicidad." (Segato 2007:197). La especificidad del pasado étnico negro fue olvidada tras su desaparición ideológica y discursiva mientras aun los sujetos descendientes de la trata de esclavos permanecían (ya sin documentarse en censos) como parte integrante del componente poblacional de la nación. El olvido se tradujo en corolario de esa desaparición (Geler 2005; Frigerio 2008) que no evitó el resguardo de las memorias de afrodescendientes en nichos externos a los canales oficiales 
de transmisión del pasado. Se conformó así una "memoria subterránea" esperando salir nuevamente a la luz y poniendo en tensión los proyectos nacionales homogenizadores ${ }^{14}$. Como sostiene Pollak (1989), "esas memorias subterráneas prosiguen su trabajo de subversión en el silencio y de manera casi imperceptible afloran en momentos de crisis a través de sobresaltos bruscos y exacerbados." Aunque esto no anula la participación que han tenido los afrodescendientes (en particular, los afroporteños), a través de sus dirigentes e intelectuales, en la "contra-esfera pública subalterna" (Geler 2010) particularmente durante la puesta en marcha del proceso de nacionalización que, según Geler, fue consensuado para olvidar y ocultar el pasado como llave para pertenecer a la nación.

Pero, como señalamos en trabajos anteriores (Monkevicius 2013), para algunos autores africanos, esta forma de dominación sobre los relatos subalternos no debe entenderse aisladamente en el contexto de las naciones receptoras de la diáspora africana, sino que se encuentra en consonancia con una "filosofía africana", con "modos africanos de autoadscripción" (Mbembe 2002) donde existe un trabajo de memoria, particularmente en relación a la trata esclavista, que se caracterizó por la "difracción". Mbembe arguye que la memoria africana sobre la esclavitud se mantuvo en un plano inconsciente, silenciada por la culpa y la propia responsabilidad africana sobre los acontecimientos. Cuando se intentó rememorar, introduciéndola en el dominio consciente, surgieron dificultades para el discurso dominante africano. Para Mbembe no existe una memoria africana de la esclavitud que constituya un "telos universal", sino la represión y el silencio sobre el pasado que se extiende a ambos lados del Atlántico. Lo cierto es que esta particular forma africana de pensar el pasado se vio constreñida por el encuadramiento de la historia nacional y el escaso margen para el disenso. El olvido de los negros en Argentina entonces se vio potenciado por la intersección de estas dos narrativas.

Cuando estas circunstancias comenzaron a revertirse, a mediados de la década de 1990 debido a la llegada de corrientes multiculturalistas (Frigerio y Lamborghini 2010), reaparecen en la escena pública significaciones del pasado que se encontraban silenciadas. Por lo tanto, es posible hablar en los últimos años de un cambio en las construcciones hegemónicas de alteridad a nivel nacional que se inserta en un entramado internacional de debate y revisión sobre la identidad, la pertenencia y los derechos de los colectivos africanos y afrodescendientes y que, a su vez, se retroalimenta con la acción de los propios grupos subalternos (particularmente a través de sus dirigentes) para operar sobre este reciente proceso de marcación/visibilización en una reconstrucción identitaria que sitúa a la memoria como fuente primera de legitimación (Hoffmann 2000) ${ }^{15}$. Estos cambios en la "lógica instituida de interrelación entre las partes" dentro de una nación (Grimson 2010) pueden ser leídos como déficits en el accionar de la "aplanadora mnemónica". El terreno de la temporalidad ya no se presenta liso ni homogéneo sino que comienzan a aparecer pliegues, ondulaciones y fisuras en relato oficial que se constituyen como versiones alternativas del pasado, memorias subalternas proclamando un espacio de legitimidad y verdad.

El siguiente apartado tendrá como objetivo delimitar teóricamente esos pasados que revelan la heterogeneidad de la temporalidad nacional (Chatterjee 2008). 


\section{LAS MEMORIAS COMO ANCLAJE CULTURAL}

El derrotero seguido hasta el momento aun no nos ha permitido especificar a qué nos referimos cuando hablamos del pasado. Antes de intentar una esquiva definición sobre esta dimensión de la temporalidad, diremos que la atención radica principalmente en la relación que establece un determinado grupo social (en este caso, aquellos que se identifican como "afros") con su pasado y aquí es donde se torna muy sugerente la categoría de memoria. Este planteo, no obstante, deja al descubierto una cuestión fundamental: ¿cuál es el aporte que una perspectiva desde el campo de la memoria puede brindar a los estudios antropológicos sobre lo "afro"? Si bien es una pregunta difícil de responder desde la extensión de este artículo, comenzaremos destacando la capacidad de las memorias para organizar, movilizar y revivificar identidades colectivas, para recrear alteridades entre grupos sociales de acuerdo a la posesión de cierto pasado, herencia o tradición, y para identificar a un determinado colectivo como "étnico" en contextos de diversidad. Por lo tanto, desde aquí proponemos contribuir a repensar temáticas extensamente abordadas por la antropología a partir del análisis de las presencias y sentidos del pasado ${ }^{16}$, ejes que comenzaremos a dilucidar en la siguiente sección.

\section{1. ¿ES POSIBLE HABLAR DE MEMORIA COLECTIVA?}

Reflexionar antropológicamente sobre las presencias y sentidos del pasado afro en el presente supone recuperar una serie de debates desde diferentes disciplinas que comienzan por interrogarse, aunque sin lograr un desarrollo teórico común, sobre la posibilidad de una "presencia ausente" y es allí donde sienta precedentes la perspectiva filosófica. En principio diremos que la noción de presencia remite inmediatamente a la célebre aporía platónica de la eikon que refiere a la memoria como parte del mundo de la imaginación en su carácter de representación de lo ausente ${ }^{17}$. Recordar consiste, entonces, en hacer presente aquello (acontecimiento, personas, lugares, etcétera) que ya no existe porque pertenece al pasado y que, por lo tanto, requiere un proceso subjetivo que, sin embargo, "se encuentra anclado en experiencias y en marcas simbólicas y materiales" (Jelin 2002:2). La recordación, por lo tanto, articula el presente con el pasado mientras sitúa estos dos planos en relación con el futuro (a manera de expectativa) uniendo las tres formas de temporalidad.

Queda por ver cómo, desde el presente, surge la presencia del pasado producto de la memoria. ¿Se trata de una mera repetición o actualización del acontecimiento o evento recordado o de un proceso complejo que implica asignar sentidos a ese pasado, interpretando los eventos, hechos o personas dentro de un determinado contexto social? En este último caso, ¿cuál sería entonces el pasado que se hace presente y qué factores determinarían la elección de cierta interpretación sobre otras? Finalmente, si hablamos de sentidos que son asignados, queda pendiente la pregunta acerca de quién o quiénes asignan esos sentidos: ¿un sujeto individual o uno colectivo? Y sobre este último punto, ¿es posible hablar de una memoria colectiva? 
Respecto a estas cuestiones diremos que algunos consensos fueron alcanzados mientras ciertas zonas grises continúan siendo objeto de grandes disputas y polémicas. Para los fines de este trabajo y considerando los objetivos expuestos, sólo esbozaremos aquellos postulados que sirvan como herramientas para dar respuesta a las preguntas aquí planteadas.

Gran parte de lo que hoy en día pareciera una verdad de perogrullo acerca de la forma en que se concibe a la memoria (su carácter construido y dinámico, la selección que explica la relación entre recuerdos y olvidos, la influencia del contexto social, cierto determinismo del presente sobre el pasado, su capacidad como marcador de la diferencia social, etcétera) tiene su origen en la lúcida aproximación al tema realizada por Maurice Halbwachs en las primeras décadas del siglo XX. Halbwachs, fiel a la tradición durkhemiana, propone una mirada social de la memoria. En el mismo movimiento en el que refuta tanto a Charles Blondel -por su postura psicologizante- como a Henri Bergson -por su concepción intuitiva y onírica de la memoria- Halbwachs plantea primero la noción de “marco social"18 para luego proponer la idea de una "memoria colectiva"19. Recuperada recién a partir de la década de 1980, su obra ha dado lugar a numerosas lecturas y relecturas, particularmente el concepto de memoria colectiva ha sido el centro de los análisis críticos.

La riqueza del enfoque de Halbwachs (1990) resulta de situar el eje de análisis ya no sobre la memoria en sí misma sino sobre los marcos sociales dentro de los cuales se produce. Por lo tanto, la memoria individual, comparable a una "ficción", exige estar enmarcada por los grupos sociales como condición de posibilidad. Así se comprende que "la noción de marco social deje de ser una noción simplemente objetiva para convertirse en una dimensión inherente al trabajo de rememoración" (Ricoeur 2004:159). Siguiendo con el razonamiento de Halbwachs, en el seno de cada grupo -desde la nación hasta una institución étnica- se desarrolla una memoria colectiva que afecta a los miembros que componen el grupo y que se anudan entre sí en una pluralidad de memorias. Queda pues un estrecho margen para un individuo que actúe como agente, conciente de los flujos sociales que preexisten al acto mnemónico ${ }^{20}$. Si bien los marcos sociales posibilitan la recordación del pasado, Halbwachs no se detiene a analizar el rol activo de la memoria en la definición y división de comunidades (Rigney 2008).

Al respecto, resta preguntarse si ese carácter social nos habilita para hablar de una memoria colectiva. La respuesta es negativa si el concepto se eleva sobre los sujetos y sus prácticas, incurriendo en una reificación con escasas posibilidades de ser utilizada como herramienta de análisis. No obstante, la respuesta es positiva si pensamos en lo colectivo de las memorias en tanto "compartidas, superpuestas, producto de interacciones múltiples, encuadradas en marcos sociales y en relaciones de poder" (Jelin 2002:22). Si bien Halbwachs no profundizó sobre los sujetos como ocupantes de distintos nichos y posiciones de poder, dio el puntapié inicial para pensar en una memoria que se construye desde lo social. Recordar, entonces, no surge de un acto pasivo de reproducción de los acontecimientos tal como fueron guardados en la mente de los individuos sino de una construcción o trabajo situado en el presente por lo que necesariamente conlleva cambio y transformación.

Creemos que las nociones de "marco social" y de "construcción" se convierten en ejes claves para el tratamiento del rol que ocupa la memoria en la definición de la identidad y de sentido de pertenencia entre 
afrodescendientes y africanos en Argentina. Por un lado, porque sitúan estos procesos mnemónicos en matrices de alteridad y diversidad delimitando lo recordado y haciéndolo susceptible también a los efectos de esa recordación; por el otro, porque en el mismo proceso de asignar sentido al pasado se produce una construcción y reconstrucción de ese pasado de acuerdo a valores y representaciones vigentes en el presente. Este último punto implica pensar en la posibilidad de múltiples construcciones o versiones del pasado y de una necesaria selección que, al mismo tiempo que confronta con el discurso monolítico estatal, pone en duda las memorias subalternas acotando su legitimidad. Aquí restaría indagar sobre la forma en que una versión se impondría sobre las demás a partir de determinados criterios de verdad y autenticidad ${ }^{21}$. Halbwachs solo destaca que aquellos acontecimientos que no encuentren un marco social que los sustente caerán irremediablemente en el olvido. Recuerdos y olvidos se articularán entonces dialécticamente haciendo posible el trabajo de memoria.

Sin embargo, la determinación del presente sobre el pasado se constituyó en un eje de discusión a la hora de comprender las prácticas mnemónicas de los diversos grupos sociales. Frente al "presentismo" algunos propusieron una perspectiva que tenga en cuenta las limitaciones que imponen un código común y una simbología que serían propios de cada época y que no resultan fácilmente transformables desde el presente (Schwartz 1982). Por lo tanto, la recordación no produciría una total discontinuidad respecto al hecho rememorado, sino que continuidad y discontinuidad serían parte del trabajo de memoria, limitando la cantidad de versiones disponibles del pasado ${ }^{22}$. Podríamos decir que la memoria encuentra anclaje en el presente pero las condiciones de su recordación-producción se hallan limitadas tanto por las posiciones sociales que ocupan los sujetos que recuerdan como por la historicidad de ese posicionamiento, que habilita contranarrativas así como determina la internalización de otras.

En resumen, resulta oportuno retomar el interjuego entre el marco social y la interpretación del pasado, la condición plural de las memorias debido a la diversidad de grupos y adscripciones a las que pertenecen los sujetos, su carácter selectivo a partir de una dialéctica entre recuerdos y olvidos que opera desde el presente y su capacidad como demarcador social. Sin embargo, las circunstancias actuales, específicamente aquellas que operan para revisibilizar grupos subalternos, impiden hablar de formaciones estables de las memorias (Huyssen 2001), a las que Joel Candau (2002) circunscribirá dentro de las llamadas "retóricas holistas". Una cita de Huyssen podrá aclarar mejor este punto:

Las cada vez más fragmentadas políticas de la memoria de los específicos grupos sociales y étnicos en conflicto dan lugar a la pregunta de si acaso son aún posibles las formas consensuadas de la memoria colectiva; de no ser así, si, y de qué manera, puede garantizarse la cohesión social y cultural sin esas formas (Huyssen 2001).

Lo social no implica lo colectivo (Candau 2002) ni lo colectivo implica lo consensuado. Al referirnos a las memorias como sociales no presuponemos un consenso necesario sino permanentemente negociado y disputado entre grupos con variada capacidad de agencia de acuerdo a las posiciones de poder que los ubican en distintos niveles sociales, y aun dentro de los grupos, como es el caso de los afro.

Si bien la experiencia de recordación es individual, el proceso de asignarle sentido requiere de entramados sociales y culturales. Por esta razón, tomamos las redefiniciones sobre la noción de memoria colectiva que hablan 
de "prácticas mnemónicas" operando en diferentes contextos sociales (Olick y Robbins 1998:112). Como señala Jelin (2002:37), "la memoria, entonces, se produce en tanto hay sujetos que comparten una cultura, en tanto hay agentes sociales que intentan 'materializar' esos sentidos del pasado en diversos productos culturales". Se trata de prácticas sociales donde se establece una determinada relación, que siempre es cultural, con el pasado desde el presente.

Retomando lo dicho hasta aquí, diremos que hablar de memoria implica pensar en una diversidad de formas de interpretar y (re)construir el pasado, por lo que se vuelve necesario reformular el término en tanto memorias, en plural ${ }^{23}$; que esas interpretaciones requieren de marcos sociales y culturales para que puedan ser activadas, narrativizadas y transmitidas; que precisan también de sujetos que transformen sus experiencias en memorias de carácter social, lo que pone en juego la intencionalidad, el trabajo de los agentes sobre el proceso de construir narrativamente el pasado; implica asimismo considerar las distintas posiciones ocupadas por los sujetos que recuerdan en el tejido social y que determinan la elección-internalización-imposición de ciertas versiones sobre otras; y finalmente, la materialización de esos sentidos en diversos recursos simbólicos que actuarán como exteriorizaciones y transmisores de las memorias y como marcas culturales de la diferencia social.

Desde aquí pensamos la memoria como un producto cultural y, en tanto cultural, público, compartido, disputado, sujeto a la interpretación situada de los agentes sociales y expresado en símbolos. Y en este aspecto es que interesa como eje de cuestionamiento antropológico. Siguiendo la propuesta de Candau (2002:35), la antropología estudia principalmente “las expresiones organizadas, ritualizadas o institucionalizadas y, por lo tanto, voluntarias de la memoria" relegando las manifestaciones espontáneas y los procesos individuales e interiores al sujeto que recuerda para ser abordados desde otras disciplinas.

\section{3. "NUEVAS" MEMORIAS FRENTE AL OLVIDO}

Si retomamos la idea de un cambio en las condiciones de comprensión y marcación de las alteridades al interior de la nación con lo postulado en el apartado anterior, podemos poner en juego de relaciones lo dicho hasta aquí y esbozar algunas reflexiones. En primer lugar, y frente al persistente proceso de invisibilización, los grupos que se autoadscriben como "afros" en las condiciones actuales necesitan reafirmar esa pertenencia identitaria mediante determinados elementos culturales, en otras palabras, "exploran elementos presentes y a la vez polisémicos de la configuración cultural para asociarlos directamente al sentido que pretenden otorgarle de la identidad." (Grimson 2010). Y en esta búsqueda, particularmente los afrodescendientes, encuentran dificultades para fijar los parámetros de la diferencia cultural en el habitus siendo que se trata de argentinos que han atravesado varias generaciones desde el acontecimiento original de la trata esclavista.

No obstante, el trabajo de investigación realizado (particularmente sobre los discursos públicos de líderes asociativos ${ }^{24}$ ) nos permitió observar la ubicuidad y la permanente apelación a la memoria como mecanismo para 
marcar alteridad y generar sentido de pertenencia. De esta manera, la resignificación del pasado africano en Argentina es puesta al servicio de los nuevos procesos de reetnicización porque creemos que la memoria actúa como potente legitimador de las prácticas culturales que actúan como categorías de identificación.

Si es desde el olvido donde el relato nacional homogenizante los ha construido como alteridad, los sujetos autoadscriptos como "afros" reconstruyen desde la memoria esa línea demarcatoria, esa diferencia que les permita identificarse y visibilizarse como "otros" ciudadanos con la capacidad de disfrutar de los mismos derechos en tanto integrantes del colectivo nacional. Se observa esa tensión a la que se refiere Hanchard (2009:45), entre el olvido impuesto por los "proyectos nacionales para enfatizar la unidad nacional, y la tenaz proyección de la memoria por actores no estatales con el objetivo de mantener vivas las historias de aquellos reprimidos y negados por el estado". Pero esas memorias no pretenden tomar el lugar del relato oficial, de manera alternativa o refractaria, sino que la disputan desde dentro, no a la manera de mera resistencia ${ }^{25}$ pasiva sino como parte del disputado “campo de las representaciones públicas de la historia" (Popular Memory Group, 1982), en un "punto de lucha contra la dominación y la discriminación" (Hoffmann, 2000). Implica asimismo la dificultad de poner en duda formas comunes de entender el pasado que han sido internalizadas a través del trabajo de aplanamiento ejercido por la historia hegemónica sobre las subalternas. Para contrarrestarla apelan principalmente a una matriz conocida, a un hito del pasado negro: la esclavitud, pero asignándole significaciones diferentes a aquellos sentidos creados por la historia oficial. Creemos, como Olick (1998:551), que no se trata solo de nuevas constelaciones de intereses que producen nuevas imágenes del pasado sino también de nuevas imágenes del pasado (en este caso, sobre el pasado esclavo y su continuidad hasta el presente) que permiten rever posiciones de poder. No obstante, esas imágenes encuentran dificultades para establecerse como parte de un relato unificado y homogéneo que dispute la narrativa nacional. Como señalamos antes, la diversidad de orígenes, procedencias, ideologías, posicionamientos sociales, políticos, etcétera, entre afrodescendientes y africanos, impiden hablar de "una memoria negra", sino de múltiples y diversificadas memorias sobre el pasado africano en Argentina. Entre ellas podemos mencionar las referencias a un pasado colonial y a la crueldad de la trata esclavista, los contrarelatos respecto a la narrativa de una nación blanca y homogénea, las alusiones legitimadoras de un origen africano, la reconstrucción de calendarios y efemérides, la revisión de conmemoraciones, entre otros. Estas narrativas y énfasis sobre determinados aspectos del pasado africano varían de acuerdo al grupo que recuerda (sean afrodescendientes, inmigrantes actuales, afroargentinos, caboverdianos, etcétera), la adscripción ideológica y política de éstos, las necesidades presentes de reparaciones y políticas públicas, y su posicionamiento frente al Estado argentino.

Sin embargo, en su pluralidad y hasta competencia, encuentran anclaje en el hecho de haber sido historias relegadas del relato monolítico oficial, el cual comienza a ser entendido, ya no como algo indiscutible y naturalizado, sino como un producto histórico, "como el resultado particular e ideológico del modo en que los bloques de poder fueron usando el pasado para autorizar y legitimar las estructuras sociales asimétricas, y para distribuir y controlar a los 'otros internos'" (Ramos 2011) y, por lo tanto, pasible de ser "revisado", "revertido", "completado"26 y apropiado. Es así como el material de la historia argentina es reinterpretado y recombinado en formas disímiles 
con el objeto de modificar las fronteras sociales en función de los combates del presente y del futuro (Pollak 1989). La subalternidad del colectivo "afro" comienza a transformarse desde la invisibilidad y la negación, con un pasado "no dicho", hacia el reconocimiento de su particularidad cultural lo que da paso a una memoria audible dirigida a la contestación y la reivindicación de los espacios sociales perdidos o no asignados desde la conformación de la nación. Y que toma como interlocutor central al estado como objeto de denuncia y reclamo de reparación moral debido a la trata esclavista. En otras palabras, la necesidad de recordar-aprender el pasado adquiere un carácter normativo donde la memoria no solo inscribe "lo que sucedió" ("memoria de") sino que informa sobre una serie de obligaciones y responsabilidades adquiridas en relación a ese pasado ("memoria para"27) que necesariamente condicionan el comportamiento presente e influyen en la vida moral de los sujetos que recuerdan (Poole 2008).

Junto con la práctica cultural de recordar se produce la materialización de ese proceso subjetivo en diversos soportes o vestigios de la memoria que comienzan a multiplicarse en los últimos años, entre ellos se cuentan las conmemoraciones de nuevos aniversarios, la reconstrucción de calendarios, las performance artísticas, los monumentos, los libros y publicaciones, etcétera, y que progresivamente requerirán de la atención académica debido a su proliferación y a su importante rol en la transmisión de las memorias afro.

En síntesis, este trabajo pretendió focalizar sobre la capacidad interpretativa de la categoría de memoria para abordar distintas problemáticas relativas al colectivo conformado por afrodescendientes y africanos en Argentina como sector subalternizado y heterogéneo cuya posición dentro de la narrativa nacional, aun subordinada, encuentra nuevos anclajes que habilitan selecciones y reinterpretaciones del pasado. 


\section{NOTAS}

1 El foco se desvió, según este autor, desde los futuros presentes a los pretéritos presentes, lo cual requiere de explicaciones en términos históricos y fenomenológicos.

2 Algunos exponentes de este movimiento son Elizabeth Jelin, Rosana Guber, Emilio Crenzel, Ludmila da Silva Catela, Claudia Feld, Federico Lorenz, Héctor Schmucler, entre otros.

3 Véase Ramos (2010).

4 Algunas de ellas son "La diáspora africana de la Argentina" o DIAFAR, la "Agrupación Xangó", el "Movimiento Afro-cultural", "La Asociación de senegaleses en Argentina", "África y su diáspora", entre otras. Fueron creadas a partir del año 2000 y se caracterizan por una gran dinámica que provoca fisiones y fusiones periódicamente. La mayoría se encuentra conformada de manera "mixta", por afrodescendientes e inmigrantes africanos.

5 Sollors (1989) se refiere a este proceso como un camuflaje del acto de invención.

6 Retomando la expresión "normalization" de Olick (1998).

7 Parafraseando la expresión de Segato sobre la construcción argentina de una "etnicidad ficticia" (2007:30).

8 Esto se ve claramente en relación a algunos grupos de inmigrantes europeos, como los lituanos que han sido alternativamente excluidos e integrados al deseado "crisol de razas".

9 Por esta época comenzó a plantearse la necesidad de inventar una "tradición nacional" que, en esta primera instancia, se puso en práctica desde los ámbitos escolares especialmente a través de los rituales de conmemoración nacional. George Mosse (2007:32) denomina a este proceso como "religión secular", cuya teología se expresa mediante la liturgia.

10 A pesar de las diferencias políticas e ideológicas que impregnaron los debates acerca de qué pasado debía ser el pasado nacional, todos los sectores involucrados concordaron sobre la relevancia de su delimitación y trasmisión ya sea para afirmar la conciencia cívica, para construir la memoria colectiva o para generar la adhesión patriótica y consolidar la nacionalidad (Bertoni 2007:119).

11 También considerada por Ribeiro (2002).

12 Véase Devoto (2003).

13 Tomando la expresión acuñada por Gustavo Lins Ribeiro (2002) en oposición al "tropicalismo" brasileño.

14 Véase Hanchard (2009).

15 Aunque Hoffmann se refiere específicamente a los procesos de demandas territoriales por parte de poblaciones negras en Colombia, creemos extensible la propuesta de la autora al caso argentino.

16 Reformulando un planteamiento de Elizabeth Jelin (2002:2).

17 Véase Ricoeur (2004: 23)

18 En su obra "Les cadres sociaux de la mémoire" de 1925.

19 En su obra póstuma "La mémoire collective" de 1950.

20 Se trata del aspecto más durkhemiano de su aproximación. Kansteiner (2002), por su parte, discute la fuerte interrelación entre lo individual y lo colectivo reclamando nuevas formas de abordaje que superen los determinismos.

21 Sólo la adscripción a ciertos grupos explicaría estas variantes según el enfoque de Halbwachs.

22 En esta línea, Arjun Appadurai (1981) se refiere al pasado como un "recurso escaso" que ha sido tradicionalmente pensado por la antropología como un campo simbólico totalmente maleable. En contra de esta postura, propone reflexionar sobre los constreñimientos culturales, las normas que limitan la "plasticidad" o invención de la significación del pasado.

23 Jelin (2002), Montesperelli (2005:15). 
Paola Carolina Monkevicius

24 Véase Monkevicius (2012).

25 Como bien sostiene Young (2001), el término "resistencia" desde el enfoque poscolonial no focaliza sobre las necesidades y las posibilidades de los movimientos intervencionistas para forzar transformaciones económicas, políticas, sociales y culturales.

26 Los tres términos entrecomillados fueron usados por líderes afrodescendientes y africanos.

27 Expresiones tomadas de Ellen Woortmann (2000). 


\section{REFERÊNCIAS BIBLIOGRÁFICAS}

ANDERSON, Benedict. 1997. Comunidades Imaginadas. México: F.C.E.

APPADURAI, Arjun. 1981. “The past as a scarse resourse". Man (N.S.) 16: 201-19.

BERTONI, Lilia Ana. 2007. Patriotas, cosmopolitas y nacionalistas. La construcción de la nacionalidad argentina a fines del siglo XIX. Buenos Aires: F.C.E.

BRIONES, Claudia. 1995. “Hegemonía y construcción de la 'nación'. Algunos apuntes”. Papeles de Trabajo 4(abril). . 1998. La alteridad del "cuarto mundo". Una deconstrucción antropológica de la diferencia. Buenos Aires: Ediciones del Sol.

. 2005. “Formaciones de alteridad: contextos globales, procesos nacionales y provinciales". En C. Briones (ed.). Cartografías Argentinas: Políticas indigenistas y formaciones provinciales de alteridad. Buenos Aires: Antropofagia. BROW, James. 1990. “Notes on community, hegemony, and the uses of the past”. Anthropological Quaterly 63(1):1-6. CANDAU, Joel. 2002. Antropología de la Memoria. Buenos Aires: Nueva Visión.

COMAROFF, John; COMAROFF, Jean. 2011. Etnicidad S. A. Madrid: Katz Editores.

CORRIGAN, Phillip; SAYER, Derek. 2007. "Introducción a la formación del Estado inglés como revolución cultural”. In: M. Lagos y P. Calla (comps.). Antropología del Estado. Dominación y prácticas contestatarias en América Latina. La Paz: PNUD.

CHATTERJEE, Partha. 2008. La nación en tiempo heterogéneo y otros estudios subalternos. Buenos Aires: Siglo XXI. DEVOTO, Fernando. (2003). Historia de la Inmigración en la Argentina. Buenos Aires, Sudamericana.

FRIGERIO, Alejandro. 2008. “De la desaparición de los negros a la reaparición de los afrodescendientes: comprendiendo la política de las identidades negras, las clasificaciones raciales y de su estudio en la Argentina". In: G. Lechini (comp.). Los estudios afroamericanos y africanos en América Latina: herencia, presencia y visiones del otro. Córdoba - Buenos Aires: Ferreyra Editor-CLACSO.

. 2010. “Sobre ‘Radiografía de la comunidad afro' en Página 12”. Blog http://alejandrofrigerio.blogspot.com/. Consultado el 24 de noviembre.

; LAMBORGHINI, Eva. 2011. “Los afroargentinos: formas de comunalización, creación de identidades colectivas y resistencia cultural y política. Aportes para el desarrollo humano en Argentina 2011". PNUD 5: 1-51.

GELER, Lea. 2005. "Afroargentinos de Buenos Aires: Recreación de una comunidad 'invisible'". In: J. Valverde del Río y S. N. Molleda (coords.). Las políticas de la memoria en los sistemas democráticos. Sevilla: Asociación Andaluza de Antropología.

2010. Andares negros, caminos blancos. Afroporteños, Estado y nación Argentina a fines del siglo XIX. Rosario: Prohistoria ediciones.

GILLIS, John. 1994. "Memory and Identiy: The History of a Relantionship". In: J. Gillis (comp.). Conmemorations: The Politics of National Identiy. Princeton: Princeton University Press.

GRIMSON, Alejandro. 2010. "Culture and Identity: two different notions". Social Identities 16(1): 63-79.

HALBWACHS, Maurice. 1990. A Memória Coletiva. Sao Paulo: Vértice.

HANCHARD. Michael. 2009. "Black Memory versus State Memory: Notes toward a Method”. Small Axe: A Caribbean Journal of Criticism 26: 45-62. 
HANDLER, Richard. 1994. "Is 'Identity' a useful cross-cultural concept?". In: J. Gillis (Comp.). Conmemorations: The Politics of National Identiy. Princeton: Princeton University Press.

HOFFMANN, Odile. 2000. "La movilización identitaria y el recurso a la memoria (Nariño, Pacífico colombiano)". In:C. Gnecco y M.Zambrano (eds.). Memorias hegemónicas, memorias disidentes. Cauca: ICAN-U.del Cauca.

HUYSSEN, Andreas. 2001. En busca del futuro perdido. Cultura y memoria en tiempos de globalización. México: F.C.E.

JAUME, Fernando. 2000. “Estrategias Políticas y Usos del Pasado en las Ceremonias Conmemorativas de la 'Masacre de Margarita Belén' 1996-1998". AVA, Revista de Antropología 2: 65-94.

JELIN, Elizabeth. 2002. Los trabajos de la memoria. Madrid: Siglo XXI Editores.

JULIANO, Dolores. 1992. "Estrategias de elaboración de la identidad". In: C. Hidalgo y L. Tamagno (Comps.). Etnicidad e Identidad. Buenos Aires: CEDAL.

KANSTEINER, Wulf. 2002. "Finding meaning in memory: A methodological critique of collective memory studies". History and Theory 41(may): 179-197.

RIBEIRO, Gustavo Lins. 2002. “Tropicalismo e Europeísmo. Modos de representar o Brasil e Argentina”. In: A. Frigerio e G. Lins Ribeiro (orgs.). Argentinos e Brasileiros: Encontros, Imagens e Estereótipos. Petrópolis: Vozes.

MBEMBE, Achille. 2002. "African Modes of Self-Writing". Public Culture 14(1): 239-273.

MONKEVICIUS, Paola. 2012. “No tenía que haber negros”: Memorias subalternas y visibilización entre afrodescendientes e inmigrantes africanos en Argentina'. Revista Publicar en Antropología X(XII): 87-105.

. 2013. “Contra la 'sentencia de la historia': Las memorias afro y las construcciones coloniales de la presencia negra en Argentina". Question 37(1): 351-358.

. No prelo. Los lituanos en Argentina. Asociacionismo y memoria. Buenos Aires: Editorial Biblos.

MONTESPERELLI, Paolo. 2005. Sociología de la memoria. Buenos Aires: Nueva Visión.

MOSSE, George. 2007. La nacionalización de las masas. Simbolismo político y movimientos de masas en Alemania desde las guerras napoleónicas al Tercer Reich. Buenos Aires: Siglo XXI Editores.

OLICK, Jeffrey. 1998. "Introduction". In: J. Olick (ed.). Social Science History. Special Issue: Memory and the Nation 22(4): 377-387.

; ROBBINS, Jocelyn. 1998. "Social Memory Studies: From “Collective Memory" to the Historical Sociology of Mnemonic Practices". Annual Review of Sociology 24: 105-140.

OLWIG, Karen. 1999. "The Burden of Heritage: Claiming a Place for a West Indian Culture". American Ethnologist 26(2): 370-388.

POLLAK, Michael. 1989. "Memória, esquecimento, silencio". Estudos Históricos 2(3): 3-15.

POOLE, Ross. 2008. "Memory, history and the claims of the past". Memory Studies 1(2): 149-166.

POPULAR MEMORY GROUP. 1982. "Popular Memory: theory, politics, method". In: R. Jonson, G. McLennan, B. Schwartz y D. Sutton (eds.). Making Histories. Studies in history writing and politics. Minneapolis: University of Minnesota Press.

RAMOS, Ana. 2010. "'The good memory of this land': Reflections on the processes of memory and forgetting". Memory Studies 3(1): 55-72. 
. 2011. "Perspectivas antropológicas sobre la memoria en contextos de diversidad y desigualdad". Alteridades 21: 131-148.

RICOEUR, Paul. 2004. La memoria, la historia, el olvido. Buenos Aires: F.C.E.

RIGNEY, Ann. 2008. "Divided pasts: A premature memorial and the dynamics of collective remembrance". Memory Studies 1(1): 89-97.

SCHWARTZ, Barry. 1982. "The Social Context of Conmemoration: A Study in Collective Memory". Social Forces 61(2): 402.

SEGATO, Rita Laura. 2007. La Nación y sus Otros. Raza, etnicidad y diversidad religiosa en tiempos de Políticas de la Identidad. Buenos Aires: Prometeo Libros.

SOLLORS, Werner. 1989. "Introduction: The Invention of Ethnicity". In W. Sollors (comp.). The Invention of Ethnicity. Oxford: Oxford University Press.

WOORTMANN, Ellen. 2000. “Identidades e Memória entre Teuto-brasileiros: Os dois lados do Atlantico". Horizontes Antropológicos. Relaciones Interétnicas 6(14): 205-238.

YOUNG, Robert. 2001. Postcolonialism. An Historical Introduction. Oxford: Blackwell. 


\section{Memórias afro descendentes e africanas na Argentina: algumas considerações teóricas}

\section{RESUMO}

Este artigo propõe repensar teoricamente algumas discussões e formas de apreensão das memórias, a partir de uma perspectiva antropológica interessada em analisar de que forma o passado é usado por grupos subalternos que se autodenominam "afros", em um contexto no qual se aprofundam as fissuras da narrativa oficial argentina e se abrem novos espaços para as "outras" memórias como fonte de visibilização e reivindicações. Portanto, propomos o objetivo de situar as memórias de afro descendentes e africanos no quadro nacional no qual atuam para delimitar e marcar as fronteiras culturais. Para isso, as memórias são enquadradas teoricamente especificando categorias e conceitos. Finalmente, reunimos as discussões apresentadas para propor uma perspectiva que contribua para o conhecimento do complexo campo dos estudos "afro" na Argentina, particularmente a respeito dos processos de invisibilização-visibilização, discriminação e pedidos de direitos e de igualdade cidadã.

PALAVRAS-CHAVE: Memória social; afro descendentes; história hegemônica; grupos subalternizados.

\section{Afro descendant and African memories in Argentina: some theoretical considerations}

\section{ABSTRACT}

This article aims at reconsidering the apprehension of memories from an anthropological perspective. The text analyzes how the past is used by subaltern groups that identify themselves as "Afro" in a context in which deepening fissures in official narratives allow "other" memories to emerge as sources of visibility and claims. We therefore propose to place the memories of Afro-descendants and African migrants in the national context where they act to delimit and highlight cultural borders. To that end we seek a theoretical framing of these memories by specifying concepts and categories. Bringing together the issues previously discussed we finally propose an anthropological perspective that may contribute to the understanding of the complex field of "Afro" studies in Argentina, particularly in regard to visibility-invisibility processes, discrimination, and rights claims.

KEY WORDS: Social memory; Afro-descendants; hegemonic history; subalternized groups.

Recebido em 03/05/2013

Aprovado em 10/01/2014 